\title{
Ultrassonografia Doppler na avaliação renal de cadelas diagnosticadas com piometra antes e após tratamento com ovariosalpingohisterectomia ${ }^{1}$
}

\author{
Roberta V. Santos ${ }^{2 *}$, Natalie B. Merlini ${ }^{3}$, Livia P. Souza², Vânia M.V. Machado², \\ José Carlos de Figueiredo Pantoja ${ }^{4}$ e Nereu C. Prestes ${ }^{2}$
}

\begin{abstract}
Santos R.V., Merlini N.B., Souza L.P., Machado V.M.V., Pantoja J.C.F. \& Prestes N.C. 2013. [Doppler ultrasonography in the renal evaluation of bitches diagnosed with pyometra before and after treatment with ovariohysterectomy.] Ultrassonografia Doppler na avaliação renal de cadelas diagnosticadas com piometra antes e após o tratamento com ovariosalpingohisterectomia. Pesquisa Veterinária Brasileira 33(5):635-642. Departamento de Reprodução Animal e Radiologia Veterinária, Faculdade de Medicina Veterinária e Zootecnia, Universidade Estadual Paulista, Distrito de Rubião Júnior s/n, Botucatu, SP 18618-970, Brazil. E-mail: robertavaleriano@yahoo.com.br

The aim of this study was evaluate the renal hemodynamics of bitches with pyometra by means of laboratory tests, ultrasound B mode and Doppler, before and after treatment with ovariohysterectomy (OSH). This study evaluated 30 bitches with pyometra, all were subjected to OSH (moment 1) and 20 were evaluated after 7 days (moment 2). The renal perfusion, the resistivity index (RI) of the main renal artery and the interlobar arteries (cranial, middle and caudal) were statistically different between times 1 and $2(p<0,05)$. There was no statistical difference for renal perfusion between the left and the right kidney at the time 1 and 2 . The correlations between the IR of the main artery and the variables used to determine renal function were stablished at the time 1. For the correlated variables: urea, creatinine, proteinuria, ratio GGT/creatinine and protein/creatinine were curvilinear and positive associations with the resistivity index of the main renal artery $(p<0,05)$, however these correlations were considered medium and weak. Comparing the RI of the main renal artery with different scores of dehydration and renal perfusion, there was statistical difference, and show increased of resistance renal in bitches with moderate reduction in renal perfusion as well as in dehydrated bitches. Were evaluated several features of renal morphology in ultrasound B mode, however, only the presence of pelvic dilatation, medullary signal and other changes as infarcts areas and diffuse hyperechoic spots in the renal cortical and medullary were statistically different from one moment to the other, most frequently at the time 2. The results of this study show that the Doppler ultrasound can identify changes of reduction in renal perfusion by color Doppler and the increasing of the resistivity index of the renal arteries in some bitches with pyometra. As well as, the ultrasound B mode, although has non-specific changes, can detect progressive renal disorders in bitches with pyometra.
\end{abstract}

INDEX TERMS: Pyometra, bitches, renal Doppler, ultrasonography B mode.

\footnotetext{
${ }^{1}$ Recebido em 17 de dezembro de 2012.

Aceito para publicação em 5 de abril de 2013.

${ }^{2}$ Depto Reprodução Animal e Radiologia Veterinária, Faculdade de Medicina Veterinária e Zootecnia (FMVZ), Universidade Estadual Paulista (Unesp), Campus de Botucatu, Distrito de Rubião Júnior s/n, Botucatu, SP 18618-970, Brasil.*Autor para correspondência: robertavaleriano@yahoo.com.br

${ }^{3}$ Departamento de Cirurgia Veterinária, FMVZ-Unesp, Distrito de Rubião Júnior s/n, Botucatu, SP.

${ }^{4}$ Departamento de Higiene Veterinária e Saúde Publica, FMVZ-Unesp, Distrito de Rubião Júnior s/n, Botucatu, SP.
}

RESUMO.- 0 objetivo do presente estudo foi avaliar a hemodinâmica renal de cadelas com piometra por meio de exames laboratoriais, ultrassonografia Modo B e Doppler, antes e após o tratamento cirúrgico com ovariosanpigohisterectomia $(\mathrm{OSH})$. Foram utilizadas 30 cadelas com diagnóstico de piometra, todas foram submetidas a OSH (momento 1) e 20 foram reavaliadas sete dias após a cirurgia (momento 2). A perfusão renal, o índice de resistividade da artéria renal principal e de cada artéria interlobar (cra- 
nial, média e caudal) foi estatisticamente diferente entre os momentos 1 e $2(p<0,05)$. Não foi observada diferença estatística para a perfusão renal entre o rim direito e esquerdo no momento 1 e 2 . As correlações entre o índice de resistividade da artéria renal principal e as variáveis utilizadas para verificar a função renal foram estabelecidas no momento 1. Para as variáveis correlacionadas ureia, creatinina, proteinúria, relação GGT/creatinina e proteína/creatinina ocorreram associações curvilíneas e positivas com o índice de resistividade da artéria renal principal $(p<0,05)$, no entanto essas correlações foram consideradas de média e fracas. Ao comparar o IR da artéria renal principal com diferentes escores de desidratação e perfusão renal, este foi estatisticamente diferente, e demonstrou aumento da resistência renal em cadelas com moderada redução da perfusão renal, assim como em cadelas desidratadas. Foram avaliadas diversas características de morfologia renal na ultrassonografia Modo B, no entanto, somente as variáveis presença de dilatação de pelve, sinal da medular e outras alterações como áreas de infartos e pontos hiperecogênicos difusos na cortical e medular renal foram estatisticamente distintas de um momento para o outro, com maior frequência no momento 2 . Os resultados do presente trabalho demonstram que a ultrassonografia Doppler pode identificar alterações de redução na perfusão renal, por meio do Doppler colorido e o aumento do índice de resistividade das artérias renais em cadelas com piometra. Assim como, a ultrassonografia modo B, embora apresente alterações inespecíficas, pode detectar alterações renais progressivas em cadelas com piometra.

TERMOS DE INDEXAÇÃO: Piometra, cadelas, Doppler renal, ultrassonografia Modo B.

\section{INTRODUÇÃO}

A piometra se refere ao acúmulo de conteúdo purulento no útero de cadelas adultas durante a fase luteal do ciclo sexual (Asheim 1965, Stone et al. 1988). A poliúria, polidipsia, letargia, vômito, anorexia e proteinúria são achados comuns em cadelas com piometra, assim como a azotemia pré-renal decorrente da desidratação (Sandholm et al. 1975, Pretzer 2008). No entanto, geralmente após o tratamento cirúrgico a poliúria e polidpsia tendem a desaparecer, e muitas vezes, cessa a investigação para as possíveis alterações renais que estas cadelas possam desenvolver, o que restringe as informações sobre a injúria renal decorrente da piometra a médio e longo prazo (Heiene et al. 2007).

Embora a etiopatogenia da doença renal em cadelas com piometra ainda não esteja completamente elucidada, o estudo de novos métodos para diagnóstico precoce de alterações renais tem permitido conduzir as pesquisas na área (Heiene et al. 2004, Heiene et al. 2007, Maddens et al. 2011).

Além dos exames laboratoriais que identificam precocemente os distúrbios renais, a ultrassonografia Doppler tem permitido o estudo em tempo real da anatomia e da hemodinâmica do fluxo sanguíneo nos rins (Szatmári et al. 2001, Novellas et al. 2007, Yoo et al. 2008). 0 estudo baseado no Doppler é útil na avaliação de distúrbios que levam ao aumento da resistência vascular dos rins, como nefrite intersticial, necrose tubular aguda, pielonefrite, dentre outros (Morrow et al. 1996, Rivers et al. 1997). Os estudos histopatológicos renais das cadelas com piometra demonstram diferentes extensões de injúria tubulointersticial nos rins destas cadelas (Heiene et al. 2001, Maddens et al. 2011).

Diante dos benefícios do Doppler na identificação precoce de alterações no fluxo sanguíneo renal, o presente estudo teve como objetivo avaliar a hemodinâmica renal de cadelas com piometra por meio de exames laboratoriais, ultrassonografia Modo B e Doppler, antes e após o tratamento com ovariosalpingohisterectomia.

\section{MATERIAL E MÉTODOS}

Este estudo atendeu aos requisitos impostos pela Comissão de Ética no uso de animais de acordo com os princípios éticos na experimentação animal da Faculdade de Medicina Veterinária e Zootecnia da Unesp, Campus Botucatu, recebendo o protocolo número 50/2010 - CEUA.

Foram avaliadas 30 cadelas diagnosticadas com piometra, de 2 a 14 anos, de 18 raças diferentes incluindo as sem raça definida, com peso médio de $19,7 \mathrm{~kg}( \pm 14,0)$, antes do tratamento com ovariosalpingohisterectomia (momento 1). Dessas cadelas, 20 foram reavaliadas após sete dias do tratamento (momento 2). 0 diagnóstico de piometra foi obtido por meio de sinais clínicos, exames laboratoriais, ultrassonografia abdominal e observação do conteúdo purulento intra-uterino no pós-cirúrgico.

Em todas as cadelas foram realizados exame clínico, hemograma, urinálise semiquantitativa, perfil bioquímico renal, proteinúria, relação proteína/creatinina, relação GGT/creatinina, ultrassonografia renal e Dopplerfluxometria renal nos momentos 1 e 2 . Todos os exames de imagem foram realizados antes das cadelas serem submetidas à sedação para evitar os possíveis efeitos das drogas anestésicas sobre a perfusão renal e os parâmetros dopplerfluxométricos.

0 grau de desidratação das cadelas foi classificado em um escore de 1 a 4, baseado no turgor cutâneo, na redução de umidade das mucosas e da córnea, retração do globo ocular, histórico de vômito, diarreia e sinais de choque: (1) menor que 5\% de desidratação (hidratação preservada), (2) de 6 a 8\% de desidratação, (3) 8 a10\% de desidratação e (4) acima de 10\% de desidratação.

Todas as cadelas foram submetidas à fluidoterapia de acordo com o grau de desidratação, antibioticoterapia (enrofloxacina ou ceftriaxona) e a ovariosalpingohisterectomia de acordo com o procedimento padrão. Para a anestesia, as cadelas foram sedadas com acepromazina ou diazepam e morfina, via intramuscular. A indução foi realizada com propofol endovenoso e a manutenção com anestesia inalatória com isofluorano. As cadelas foram mantidas em tratamento com antibioticoterapia por 7 dias e analgésicos durante 3 dias.

Os rins direito e esquerdo foram avaliados ultrassonograficamente por um único observador, nos momentos 1 e 2, em todas as cadelas, para posterior comparação. As características e os critérios de avaliação foram: arquitetura renal 1 = preservada, 2 = não preservada; contorno renal 1 = regular, 2 = parcialmente irregular, 3 = irregular; ecotextura renal 1 = homogênea, 2 = heterogênea; dilatação de pelve 1 = presente, 2 = ausente; sinal da medular $1=$ presente, 2 = ausente; definição corticomedular 1 = preservada, 2 = moderadamente preservada, 3 = não preservada; relação corticomedular 1 = preservada, 2 = não preservada; calcificação de 
divertículos 1 = presente, 2 = ausente; outras alterações (áreas de infartos renais, pontos hiperecogênicos na cortical ou na medular) 1 = presente, 2 = ausente; ecogenicidade da cortical $1=$ preservada, 2 = aumentada, $3=$ diminuída, $4=$ mista.

Foi realizada a mensuração do comprimento renal por meio de cortes ultrassonográficos no plano longitudinal que representasse a maior extensão renal. Foram obtidas três mensurações consecutivas do comprimento renal nos momentos 1 e 2 , e realizada a média dos valores para que o resultado fosse mais fidedigno e então comparados.

A perfusão renal foi avaliada por meio da técnica de ultrassonografia Doppler colorido do aparelho MyLab 30 Gold, com probe micro convexa de 5 a $8 \mathrm{MHz}$, ajustando a caixa colorida sobre o rim esquerdo e direito, configurando o menor PRF (taxa de repetição de pulso) sem que ocorresse artefato de aliasing e com filtro de parede de $50-100 \mathrm{~Hz}$ para reduzir a formação de ruídos. A perfusão em ambos os rins foi classificada de 1 a 4 de forma semiquantitativa de acordo com o grau de visibilização das artérias e veias que compõem os rins (artérias interlobulares, arqueadas, interlobares e renais): 1 = preservada, $2=$ - discretamente reduzida, 3 = moderadamente reduzida, 4 = gravemente reduzida.

0 exame de ultrassonografia Doppler pulsado foi realizado em ambos os momentos. Após a identificação das artérias com o Doppler colorido, o volume de amostra de $2 \mathrm{~mm}$ de tamanho (ajustado quando necessário) foi posicionado sobre as artérias renais na entrada do hilo renal e sobre as artérias interlobares na região cranial, média e caudal de ambos os rins, o ângulo de insonação foi ajustado para o sentido do vaso sem ultrapassar o valor de $60^{\circ}$.

Os espectros de onda de cada artéria de ambos os rins foram obtidos e selecionados aqueles que possuíam três ondas consecutivas de qualidade, sem interferência de artefatos. 0 pico de velocidade sistólica e a velocidade diastólica final foram identificados em cada onda do espectro resultando em três valores de IR (índice de resistividade) calculados pelo aparelho para cada artéria. A partir destes três valores foram obtidas as médias e medianas do IR para cada artéria avaliada. 0 valor limítrofe para normalidade de IR considerado foi de 0,7 .

A análise estatística foi realizada por meio do programa estatístico SAS versão 9.2 (SAS Institute, 2009). Foram obtidas as médias, medianas e desvio padrão de todas as variáveis para ambos os rins e momentos.

0 teste de Postos de Sinais de Wilcoxon para amostras pareadas foi utilizado para verificar se havia diferença estatística significante entre os momentos 1 e 2 para as seguintes variáveis: exames laboratoriais, perfusão renal, IR das artérias e comprimento renal. 0 referido teste também foi utilizado para comparar o índice de resistividade das artérias renais principais e interlobares (cranial, média e caudal) entre si em cada momento. 0 valor de significância estatístico considerado foi de $\mathrm{p}<0,05$.

0 Teste de Kruskal-Wallis foi utilizado para comparar as medianas do IR da artéria renal principal entre os escores de perfusão renal, assim como para os escores de desidratação no momento 1.

As correlações entre o índice de resistividade da artéria renal principal e as variáveis ureia, creatinina, relação proteína/creatinina, relação GGT/creatinina, proteinúria e densidade urinária no momento 1 foram obtidas por regressão linear e expressas na forma de gráficos de dispersão.

Para avaliar as alterações na morfologia renal, o Teste de Qui-Quadrado foi utilizado para verificar se a distribuição dos escores era diferente entre os rins direito e esquerdo e o Teste de Associação de McNemar para verificar se havia diferença entre os momentos 1 e 2 .

\section{RESULTADOS}

Foram avaliadas 30 cadelas com piometra e reavaliadas 20, visto que 6 cadelas vieram a óbito e 4 não compareceram ao retorno. Ao comparar os exames laboratoriais no momento 1 e 2 não foram encontradas diferenças estatísticas $(p<0,05)$ apenas para as variáveis hematócrito, ureia e creatinina. As variáveis contagem de leucócitos totais, presença de desvio á esquerda, presença de neutrófilos tóxicos, presença de anemia regenerativa, contagem de plaquetas, relação proteína/creatinina, relação GGT/creatinina, proteinúria e densidade urinária apresentaram diferença estatística significante entre os momentos $(\mathrm{p}<0,05)$. Os valores da média, mediana e desvio padrão das principais variáveis comparadas entre os momentos estão dispostos no Quadro 1.

Quadro 1. Valores da média, mediana e desvio padrão das variáveis ureia, creatinina, hematócrito, plaquetas, contagem de leucócitos totais, relação proteína/creatinina, relação GGT/creatinina, proteinúria e densidade urinária para as cadelas acometidas com piometra no momento $1(n=30)$ e no momento $2(n=20)$

\begin{tabular}{|c|c|c|c|c|c|c|}
\hline & \multicolumn{3}{|c|}{ Momento $1(n=30)$} & \multicolumn{3}{|c|}{ Momento $2(n=20)$} \\
\hline & Média & Mediana & $\begin{array}{l}\text { Desvio } \\
\text { Padrão }\end{array}$ & Média & Mediana & $\begin{array}{l}\text { Desvio } \\
\text { Padrão }\end{array}$ \\
\hline Ureia (mg/dL) & 84,19 & 39,50 & 114,89 & 33,7 & 32 & 13,11 \\
\hline na $(\mathrm{mg} / \mathrm{dL})$ & 1,33 & 0,91 & 1,01 & 0,857 & 0,83 & 0,24 \\
\hline ócrito (\%) & 32,80 & 32,00 & 8,57 & 30,16 & 30 & 5,50 \\
\hline Plaquetas $(/ \mu \mathrm{L})^{*}$ & 206467 & 191000 & 128722 & 279645 & 303000 & 124119 \\
\hline Leucócitos $(/ \mu \mathrm{L})^{*}$ & 32100 & 26550 & 17460 & 12231 & 9900 & 5111,01 \\
\hline $\begin{array}{l}\text { Relação proteina/ } \\
\text { creatinina* }\end{array}$ & 1,27 & 0,68 & 1,34 & 0,39 & 0,14 & 0,77 \\
\hline $\begin{array}{l}\text { Relação GGT/ } \\
\text { creatinina* }\end{array}$ & 13,65 & 2,29 & 41,73 & 2,55 & 1,25 & 2,86 \\
\hline $\begin{array}{l}\text { Proteinúria } \\
\text { (mg/dL)* }\end{array}$ & 59,79 & 41,70 & 58,73 & 37,76 & 12,15 & 76,04 \\
\hline Densidade urinária* & 1016 & 1015 & 9 & 1023 & 1020 & 9,64 \\
\hline
\end{tabular}

Momento 1 = dia do diagnóstico e cirurgia de OSH. Momento $2=7$ dias após o momento 1. *Apresentaram diferença estatística significante. Valor de significância considerado $\mathrm{p}<0,05$.

No momento 1, 67\% das cadelas apresentavam anemia, $63 \%$ sinais de regeneração das células vermelhas e 33\% estavam trombocitopênicas. Apenas $23 \%$ das cadelas estavam azotêmicas no momento do diagnóstico de piometra e $64 \%$ das cadelas apresentavam algum grau de desidratação. Sessenta e três por cento das cadelas apresentavam leucocitose com desvio a esquerda e em 53\% dos casos havia a presença de neutrófilos tóxicos. Para relação proteína/creatinina, 63\% das cadelas apresentavam valores maiores do que 0,5 , sendo que destas 36\% apresentavam valores acima de 1,0. Já para relação GGT/creatinina, apenas $20 \%$ das cadelas apresentaram valores aumentados. Cinquenta e três por cento das cadelas apresentavam densidade urinária $\leq 1.015$ e $30 \%$ entre 1.015 e 1.025 .

No momento 2, 84\% das cadelas apresentavam hematócrito baixo $(<37 \%)$ e $89 \%$ sinais de regeneração das células vermelhas. Apenas uma cadela estava azotêmica no retorno. Entre as cadelas que vieram a óbito, 5 estavam azotemicas e 1 veio a óbito por traumatismo. Quinze por cento das cadelas ainda apresentavam leucocitose por neutrofilia no retorno, porém nenhuma delas apresentava desvio a es- 
querda ou neutrófilos tóxicos. Dezesseis por cento estavam trombocitopênicas. Para relação proteína/creatinina, 10\% das cadelas ainda mantiveram os valores acima de 0,5 , enquanto para relação GGT/creatinina, apenas 3\% das cadelas ainda apresentavam valores aumentados. No entanto, $50 \%$ das cadelas ainda mantiveram a densidade urinária $\leq 1.015$

A perfusão renal, o índice de resistividade da artéria renal principal e de cada artéria interlobar (cranial, média e caudal) foi estatisticamente diferente entre os momentos 1 e 2 ( $\mathrm{p}<0,05)$, conforme Quadro 2. Não foi observada diferença estatística para a perfusão renal entre o rim direito e esquerdo no momento 1 e no momento 2 , de forma que os resultados no Quadro 2 correspondem aos valores de ambos os rins.

Quadro 2. Valores da média, mediana e desvio padrão das variáveis perfusão renal e índice de resistividade das artérias renais principais e das artérias interlobares cranial, média e caudal para ambos os rins nas cadelas acometidas com piometra no momento 1 e no momento 2

\begin{tabular}{|c|c|c|c|c|c|c|}
\hline & \multicolumn{3}{|c|}{ Momento 1} & \multicolumn{3}{|c|}{ Momento 2} \\
\hline & Média & Mediana & $\begin{array}{l}\text { Desvio } \\
\text { Padrão }\end{array}$ & Média & Mediana & $\begin{array}{l}\text { Desvic } \\
\text { Padrã }\end{array}$ \\
\hline Perfusão Renal* & 2,46 & 2 & 1,15 & 1,74 & 1 & 1,19 \\
\hline $\begin{array}{l}\text { IR Artéria Renal } \\
\text { Principal* }\end{array}$ & 0,71 & 0,70 & 0,08 & 0,63 & 0,63 & 0,06 \\
\hline $\begin{array}{l}\text { IR Artéria Interlobar } \\
\text { Cranial* }\end{array}$ & 0,69 & 0,65 & 0,08 & 0,63 & 0,62 & 0,06 \\
\hline $\begin{array}{l}\text { IR Artéria Interlobar } \\
\text { Média* }\end{array}$ & 0,69 & 0,67 & 0,09 & 0,63 & 0,64 & 0,05 \\
\hline $\begin{array}{l}\text { IR Artéria Interlobar } \\
\text { Caudal* }\end{array}$ & 0,69 & 0,66 & 0,08 & 0,62 & 0,62 & 0,05 \\
\hline
\end{tabular}

Momento 1 = dia do diagnóstico e cirurgia de OSH. Momento $2=7$ dias após o momento 1 . Escore de perfusão renal: 1 = preservada, $2=$ discretamente reduzida, $3=$ moderadamente reduzida, $4=$ gravemente reduzida. *Apresentaram diferença estatística significativa. Valor de significância considerado $\mathrm{p}<0,05$.

Devido a redução da perfusão renal, não foi possível obter os valores do IR das artérias interlobares cranial, média e caudal de 6 rins direito e 4 rins esquerdo do grupo experimental (54/60 rins direito e 56/60 rins esquerdo avaliados), já o IR da artéria renal principal não foi obtido no rim direito de 6 cadelas (54/60 rins direito e 60/60 rins esquerdo avaliados).

O IR da artéria renal e das artérias interlobares cranial, média e caudal foram comparadas entre si dentro de cada momento. Não foi observada diferença estatística entre os valores de IR das artérias interlobares cranial, média e caudal no momento 1 e 2 , assim como na comparação entre o IR da artéria renal principal e as demais artérias no momento 2. No entanto, no momento 1 foi encontrada diferença estatística significante entre o IR da artéria renal principal e os índices de resistividade das artérias interlobares cranial $(\mathrm{p}=0,01)$, média $(\mathrm{p}=0,04)$ e caudal $(\mathrm{p}=0,003)$, ou seja, embora estas não sejam diferentes entre si, apresentam diferença significativa para a artéria renal principal.

No momento 1 , em $43 \%$ das cadelas o IR da artéria renal estava maior do que 0,7 , assim como em $33 \%$ das cadelas o IR da artéria interlobar cranial e caudal estava altera- do e em $38 \%$ das cadelas o IR da artéria interlobar média estava aumentado. No momento 2 , as porcentagens foram de $10 \%, 14 \%, 8 \%$ e $8 \%$ para a artéria renal principal, interlobar cranial, média e caudal, respectivamente.

0 IR da artéria renal principal no momento 1 foi diferente entre os escores de perfusão renal $(p=0,001)$ e do escore de grau de desidratação $(\mathrm{p}=0,001)$. A distribuição das médias dos valores do índice de resistividade artéria renal por escore de perfusão está demonstrada no Quadro 3 , enquanto a distribuição por escore de desidratação segue no Quadro 4.

Quadro 3. Distribuição do número de cadelas avaliadas e a média do índice de resistividade da artéria renal principal por escore de perfusão renal no momento 1

\begin{tabular}{|c|c|c|}
\hline \multirow{2}{*}{$\begin{array}{l}\text { Escore de Per- } \\
\text { fusão Renal }\end{array}$} & \multicolumn{2}{|c|}{ Momento 1} \\
\hline & $\begin{array}{l}\text { Número de cade- } \\
\text { las avaliadas }\end{array}$ & $\begin{array}{l}\text { Média de Índice de } \\
\text { Resistividade da Ar- } \\
\text { téria Renal Principal }\end{array}$ \\
\hline 1 & 7 & $0,63^{*}$ \\
\hline 2 & 10 & $0,67^{*}$ \\
\hline 3 & 9 & $0,74^{*}$ \\
\hline 4 & 4 & $0,79^{*}$ \\
\hline
\end{tabular}

Momento 1 = dia do diagnóstico e cirurgia de OSH. *Apresentaram diferença estatística. Valor de significância considerado $p<0,05$. Escore: $1=$ preservada, 2 = discretamente reduzida, $3=$ moderadamente reduzida, 4 = gravemente reduzida.

Quadro 4. Distribuição do número de cadelas avaliadas e a média do índice de resistividade da artéria renal principal por escore de grau de desidratação dos animais no momento 1

\begin{tabular}{ccc} 
Escore de Grau & \multicolumn{2}{c}{ Momento 1 } \\
\cline { 2 - 3 } de Desidratação & $\begin{array}{c}\text { Número de ca- } \\
\text { delas avaliadas }\end{array}$ & $\begin{array}{r}\text { Média de Índice de } \\
\text { Resistividade da Ar- } \\
\text { téria Renal Principal }\end{array}$ \\
\hline 1 & 11 & $0,64^{*}$ \\
2 & 10 & $0,71^{*}$ \\
3 & 2 & $0,78^{*}$ \\
4 & 7 & $0,79^{*}$
\end{tabular}

Momento 1 = dia do diagnóstico e cirurgia de OSH. *Apresentaram diferença estatística. Valor de significância considerado $\mathrm{p}<0,05.1=$ menor que $5 \%$ de desidratação, 2 = de 6-8\% de desidratação, $3=8-10 \%$ de desidratação e 4 = acima de $10 \%$ de desidratação.

As correlações entre o índice de resistividade da artéria renal e as variáveis utilizadas para verificar a função renal foram estabelecidas no momento 1 . Para as variáveis correlacionadas ureia, creatinina, proteinúria, relação GGT/ creatinina e relação proteína/creatinina ocorreram associações curvilíneas e positivas com o índice de resistividade da artéria renal principal $(\mathrm{p}<0,05)$, no entanto essas correlações foram consideradas de média e fracas como demonstram Figura 1, 2, 3, 4 e 5, respectivamente. Já a variável densidade urinária não apresentou associação com o índice de resistividade da artéria renal principal $(p=0,08)$, Figura 6.

As características morfológicas e o comprimento renal foram avaliados no exame ultrassonográfico modo B nos dois momentos. Embora a mediana do comprimento renal 


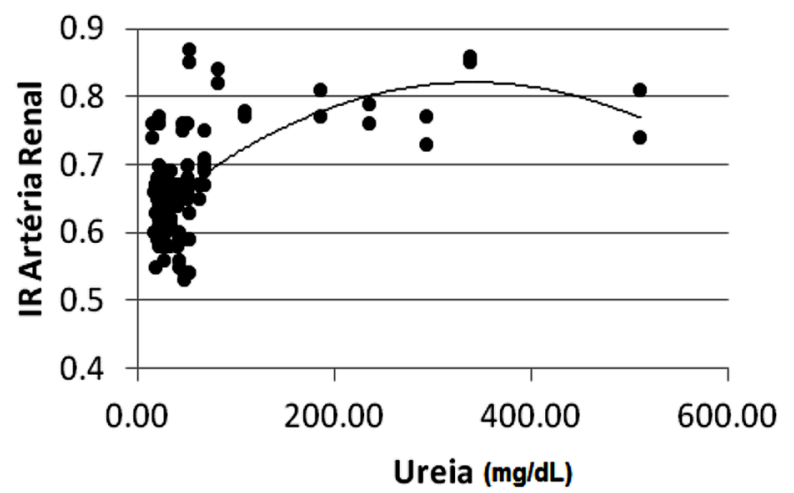

Fig.1. Correlação entre os valores de ureia e o IR da artéria renal no momento $1\left(r^{2}=0,40, p=0,0001\right)$.

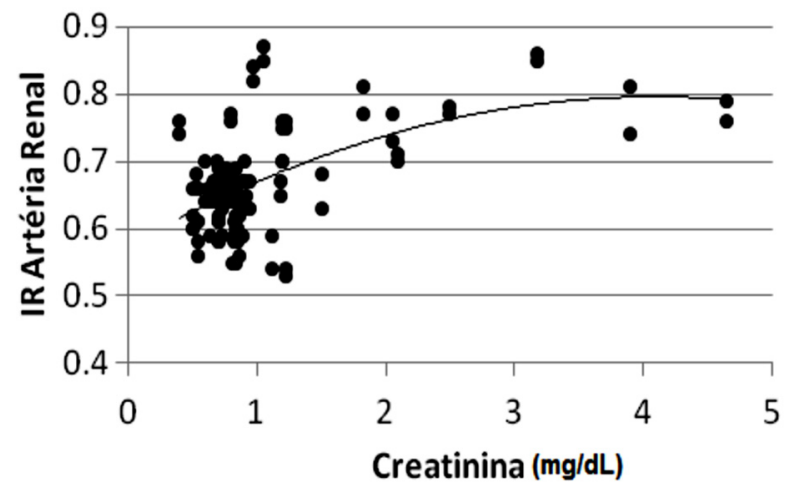

Fig.2. Correlação entre os valores de creatinina e o IR da artéria renal no momento $1\left(r^{2}=0,31, p=0,0001\right)$.

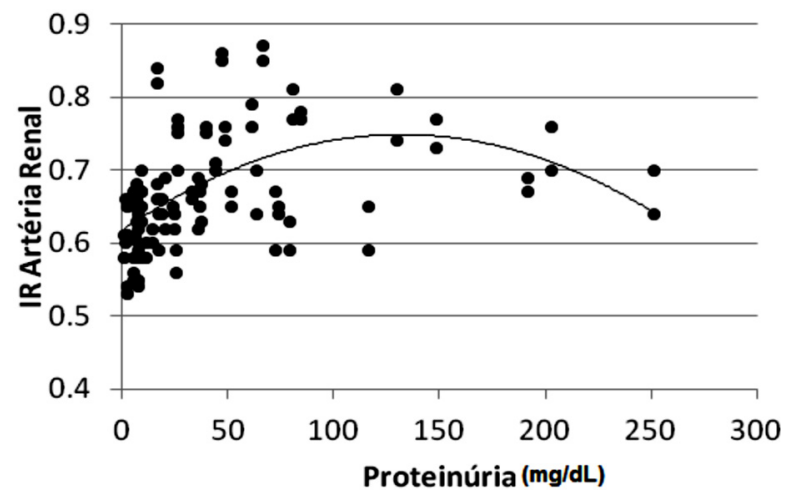

Fig.3. Correlação entre os valores de proteinúria e o IR da artéria renal no momento $1\left(r^{2}=0,11, p=0,03\right)$.

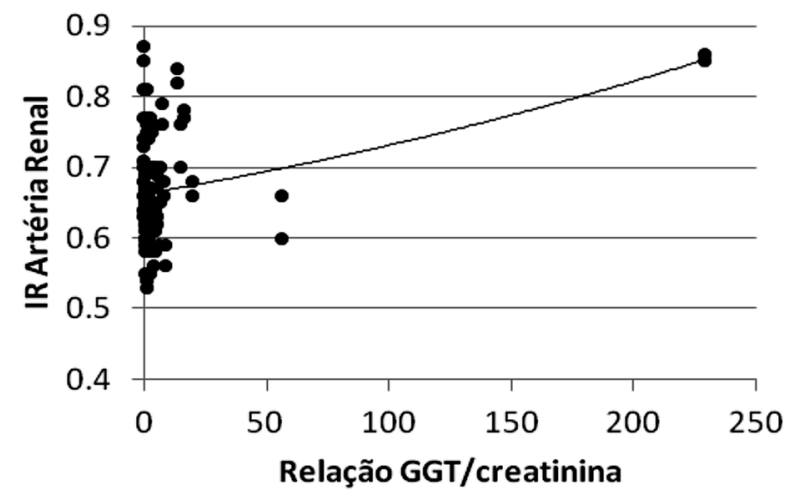

Fig.4. Correlação entre os valores de relação GGT/creatinina e o IR da artéria renal no momento $1\left(\mathrm{r}^{2}=0,1, \mathrm{p}=0,01\right)$.

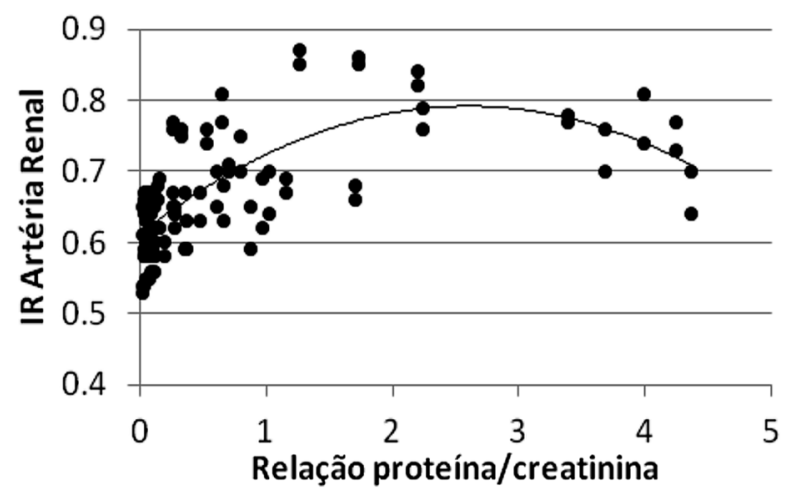

Fig.5. Correlação entre os valores de relação proteína/creatinina e o IR da artéria renal no momento $1\left(\mathrm{r}^{2}=0,34\right.$, $\mathrm{p}=0,0002)$.

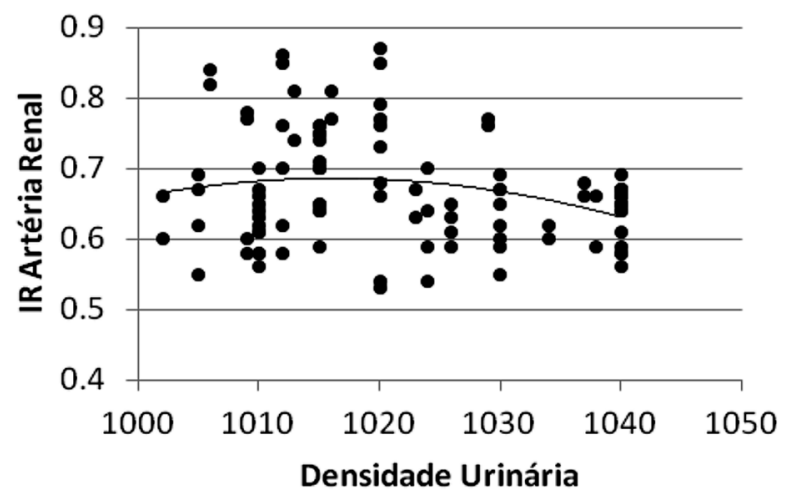

Fig.6. Correlação entre os valores de densidade urinária e o IR da artéria renal no momento $1\left(r^{2}=0,05, p=0,08\right)$.

não tenha sido estatisticamente diferente entre o rim direito e esquerdo em cada momento, esta foi diferente do momento 1 para o momento $2(\mathrm{p}=0,005)$. No momento 1 , o rim direito apresentou $6,24 \mathrm{~cm}( \pm 1,51)$, já no momento 2 a mediana do comprimento renal foi de $6,26 \mathrm{~cm}( \pm 1,0)$, enquanto o rim esquerdo apresentou $5,85 \mathrm{~cm}( \pm 1,52)$ no momento 1 e no momento 2 apresentou $6,02 \mathrm{~cm}( \pm 1,22)$ de comprimento renal.

Ao comparar as características que avaliavam a morfologia renal entre o rim esquerdo e o rim direito de cada cadela em ambos momentos, não foi observado diferença estatística para as variáveis $(\mathrm{p}=0,6)$.

A avaliação da arquitetura renal $(\mathrm{p}=0,7)$, do contorno renal $(p=0,8)$ e da definição corticomedular $(p=0,9)$ foi realizada por escores considerando $1=$ preservada, $2=$ parcialmente preservada e 3 = não preservada, porém não ocorreu diferença estatisticamente significante entre os momentos 1 e 2 . A porcentagem de cada avaliação está disposta no Quadro 5.

As características morfológicas renais ecotextura renal $(\mathrm{p}=0,009)$ e relação corticomedular $(\mathrm{p}=1,0)$ foram classificadas em homogênea e heterogênea, e preservada e não preservada, respectivamente. Somente a variável ecotextura renal apresentou diferença entre os momentos 1 e 2 . No momento 1, 42,4\% (25/59 rins) das cadelas possuíam ecotextura renal homogênea e 55,9\% (33/59 rins) mantiveram a relação corticomedular integra (59 rins). Já no momento $2,38,5 \%$ (15/39 rins) das cadelas possuíam ecotextura re- 
Quadro 5. Distribuição dos escores de alteração na morfologia renal quanto a arquitetura, o contorno e a definição corticomedular nas cadelas no momento 1 e 2

\begin{tabular}{|c|c|c|c|c|c|c|}
\hline \multirow[t]{2}{*}{ Escore } & \multicolumn{2}{|c|}{$\begin{array}{l}\text { Arquitetura } \\
\text { renal }\end{array}$} & \multicolumn{2}{|c|}{$\begin{array}{l}\text { Contorno } \\
\text { renal }\end{array}$} & \multicolumn{2}{|c|}{$\begin{array}{l}\text { Definição cor- } \\
\text { ticomedular }\end{array}$} \\
\hline & M 1 & M 2 & M 1 & M 2 & M 1 & M 2 \\
\hline 1 & $\begin{array}{c}44,1 \% \\
(26)\end{array}$ & $\begin{array}{c}35,9 \% \\
(14)\end{array}$ & $\begin{array}{c}64,4 \% \\
(38)\end{array}$ & $\begin{array}{c}58,9 \% \\
(23)\end{array}$ & $\begin{array}{c}23,7 \% \\
(14)\end{array}$ & $\begin{array}{c}28,2 \% \\
(11)\end{array}$ \\
\hline 2 & $\begin{array}{c}40,7 \% \\
(24)\end{array}$ & $\begin{array}{c}43,6 \% \\
(17)\end{array}$ & $\begin{array}{c}28,8 \% \\
(17)\end{array}$ & $\begin{array}{c}30,8 \% \\
(12)\end{array}$ & $\begin{array}{c}54,2 \% \\
(32)\end{array}$ & $\begin{array}{c}51,3 \% \\
(20)\end{array}$ \\
\hline 3 & $\begin{array}{c}15,3 \% \\
(9)\end{array}$ & $\begin{array}{c}20,5 \% \\
(8)\end{array}$ & $\begin{array}{c}6,8 \% \\
(4)\end{array}$ & $\begin{array}{c}10,3 \% \\
(4)\end{array}$ & $\begin{array}{c}22,0 \% \\
(13)\end{array}$ & $\begin{array}{c}20,5 \% \\
(8)\end{array}$ \\
\hline
\end{tabular}

M1 = dia do diagnóstico e cirurgia de OSH (59 rins). M2 = Momento 2 (39 rins) ( 7 dias após o M1). Escore: 1 = preservada, 2 = parcialmente preservada, 3 = não preservada.

nal homogênea, enquanto 66,7\% (26/39 rins) mantiveram a relação corticomedular integra. Em uma cadela não foi possível realizar o exame ultrassonográfico adequado do rim direito devido ao grande porte e temperamento do animal no momento 1 e 2 .

As variáveis presença de dilatação de pelve, sinal da medular, calcificação de divertículos e outras alterações como áreas de infartos e pontos hiperecogênicos difusos na cortical e medular renal foram classificadas em $1=$ presente, 2 = ausente. A frequência de distribuição das variáveis em cada cadela para o escore utilizado como critério para avaliar a morfologia renal em cada momento estão dispostas no Quadro 6. A maioria das características foi diferente estatisticamente de um momento para o outro $(\mathrm{p}<0,05)$, são elas: presença de dilatação de pelve $(p<0,01)$, de sinal da medular $(\mathrm{p}<0,005)$ e de outras alterações $(\mathrm{p}<0,01)$. Todas as variáveis apresentaram aumento na frequência no momento 2 .

A avaliação da ecogenicidade da cortical renal foi realizada comparativamente a ecogenicidade do parênquima hepático e esplênico para os rins direito e esquerdo, respectivamente. Não houve diferença estatística significante entre os momentos 1 e 2 para esta variável $(p=0,06)$. A distribuição da classificação da ecogenicidade renal para cada momento esta apresentada no Quadro 7.

A avaliação do rim direito nas cadelas com piometra com grande volume uterino e nas cadelas de maior porte apresentou maior dificuldade de realização, principalmen-

Quadro 6. Distribuição dos escores de alteração na morfologia renal quanto a presença ou ausência de dilatação de pelve, sinal da medular, calcificação de divertículos e outras alterações das cadelas no momento 1 e 2

\begin{tabular}{|c|c|c|c|c|c|c|c|c|}
\hline \multirow[t]{2}{*}{ Escore } & \multicolumn{2}{|c|}{$\begin{array}{c}\text { Dilatação } \\
\text { de pelve }\end{array}$} & \multicolumn{2}{|c|}{$\begin{array}{l}\text { Sinal da } \\
\text { medular }\end{array}$} & \multicolumn{2}{|c|}{$\begin{array}{c}\text { Calcificação de } \\
\text { divertículos }\end{array}$} & \multicolumn{2}{|c|}{$\begin{array}{c}\text { Outras } \\
\text { alterações }\end{array}$} \\
\hline & M 1 & M 2 & M1 & M 2 & M 1 & M 2 & M 1 & M 2 \\
\hline 1 & $\begin{array}{c}8,5 \% \\
(5)^{*}\end{array}$ & $\begin{array}{c}15,4 \% \\
(6)^{*}\end{array}$ & $\begin{array}{c}22,0 \% \\
(13)^{*}\end{array}$ & $\begin{array}{c}35,9 \% \\
(14)^{*}\end{array}$ & $\begin{array}{c}40,7 \% \\
(24)\end{array}$ & $\begin{array}{l}58 \% \\
(24)\end{array}$ & $\begin{array}{c}18,6 \% \\
(11)^{*}\end{array}$ & $\begin{array}{c}28,2 \% \\
(11)^{*}\end{array}$ \\
\hline 2 & $\begin{array}{l}91,5 \% \\
(54)^{*}\end{array}$ & $\begin{array}{l}84,6 \% \\
(33)^{*}\end{array}$ & $\begin{array}{l}78 \% \\
(46)^{*}\end{array}$ & $\begin{array}{l}64,1 \% \\
(25)^{*}\end{array}$ & $\begin{array}{c}59,3 \% \\
(35)\end{array}$ & $\begin{array}{l}42 \% \\
(15)\end{array}$ & $\begin{array}{l}81,4 \% \\
(48)^{*}\end{array}$ & $\begin{array}{c}71,8 \% \\
(28)^{*}\end{array}$ \\
\hline
\end{tabular}

M1: dia do diagnóstico e cirurgia de OSH (59 rins). M2- Momento 2 (39 rins) (7 dias após o M1). * Apresentaram diferença estatística. Valor de significância considerado p<0,05. M1- Momento 1, M2- Momento 2. Escore: 1- Presente, 2- Ausente. Outras alterações: áreas de infartos e pontos hiperecogênicos difusos na cortical e/ou medular renal.
Quadro 7. Distribuição do escore de ecogenicidade da cortical renal das cadelas no momento 1 e 2

\begin{tabular}{lcccc}
\hline Momento & \multicolumn{4}{c}{ Ecogenidade da Cortical Renal } \\
\cline { 2 - 5 } & 1- Preservada & 2 - Aumentada & 3 - Diminuída & 4 - Mista \\
\hline 1 (59rins) & $47,5 \%(28)$ & $20,3 \%(12)$ & $20,3 \%(12)$ & $10 \%(7)$ \\
2 (39 rins) & $64,1 \%(25)$ & $18,0 \%(7)$ & $2,6 \%(1)$ & $15,4 \%(6)$
\end{tabular}

M1 = dia do diagnóstico e cirurgia de 0SH. M2 = Momento 2 (7 dias após o M1).

te para obter os valores do índice de resistividade e a perfusão renal.

\section{DISCUSSÃO}

As alterações hematológicas deste experimento foram condizentes com a literatura (Smith 2006, Pretzer 2008). No entanto, as alterações nos níveis séricos de ureia e creatinina, consideradas comuns em cadelas com piometra, foram encontradas em apenas $23 \%$ das cadelas.

O estudo realizado por Bartoskova et al. (2007) avaliou os parâmetros hematológicos em cadelas com piometra antes e após a OSH em um intervalo de sete dias, assim como neste estudo. Para os autores, a OSH e a antibioticoterapia foi suficiente para melhorar todos os parâmetros hematológicos. Neste estudo, no momento 2, um número maior de cadelas apresentavam valores menores do que a normalidade para o hematócrito, porém a maioria delas apresentavam sinais de regeneração das células vermelhas. Este achado pode contestar a eficácia da antibioticoterapia utilizada neste experimento, já que a anemia pode estar relacionado a hiperatividade do sistema mononuclear fagocitário ou a liberação de citocinas endógenas que alteram o metabolismo do ferro, o que leva a redução da sobrevida das hemáceas e da eritropoiese (Cançado \& Chiattone 2002). Pode-se ainda sugerir grandes perdas sanguíneas durante o procedimento cirúrgico.

Segundo Maddens et al. (2010), 12\% das cadelas com piometra apresentam proteinúria persistente após a cirurgia. Neste estudo, a relação proteína/creatinina estava aumentada em $63 \%$ das cadelas no momento 1 e se manteve em $10 \%$ das cadelas no momento 2 . Quando a proteinúria está associada à grande quantidade de células inflamatórias, é difícil certificar-se da origem da proteinúria (Hardy \& Osborne 1974). Porém, o estudo realizado por Beatrice et al. (2010), assim como no estudo de Maddens et al. (2010), a bacteriúria não foi relacionada à alterações nos valores da relação proteína/creatinina. Neste estudo, não foi realizada a análise do sedimento urinário, o que pode comprometer a proposta de origem renal para as alterações da relação proteína/creatinina. No entanto, diante dos resultados de pesquisas prévias, e do fato das amostras terem sido obtidas por cistocentese, a proposta de origem renal para as alterações nas cadelas deste experimento ainda é pertinente.

Os níveis de GGT/creatinina na urina das cadelas foi relativamente baixo. Esta enzima esta relacionada a lesões de origem tubular (Heiene et al. 2001). No entanto, esta variável pode sofrer interferência do congelamento, segundo Heiene (1993), pode ocorrer a diminuição destes valores em até $15 \%$ nas amostras. Dessa forma, os baixos níveis da 
relação GGT/creatinina podem estar subestimados nesta pesquisa. Porém, as cadelas com quadros mais graves de injúria renal, apresentaram valores acentuados desta relação, o que é condizente com os achados na literatura.

Para Novellas et al. (2007), as alterações do IR deveriam ser maiores nas artérias intrarrenais em relação a artéria renal principal. No presente estudo, não foi observado diferença estatística entre as artérias interlobares no momento 1 e 2 , assim como entre estas e a artéria renal principal no momento 2. No entanto, o IR da artéria renal principal no momento 1 foi estatisticamente diferentes das artérias interlobares, porém distintamente do proposto pelos autores, já que o aumento do IR foi maior na artéria renal do que nas demais artérias intrarrenais, principalmente para as artérias interlobares craniais e caudais.

A hipovolemia decorrente da desidratação cursa com a diminuição da perfusão renal, a qual esta relacionada a isquemia e hipóxia renal. Segundo Ross (2011), a injúria renal aguda pode ser dividida em 4 fases, porém as alterações laboratoriais só se tornam mais evidentes na fase 3 , enquanto a fase 4 cursa com a recuperação renal. Neste estudo, as cadelas desidratadas e com maior redução da perfusão renal apresentaram aumento do índice de resistividade renal, o que demonstra o aumento da resistência ao fluxo sanguíneo renal. Dessa forma, pode se sugerir que alterações decorrentes da redução da perfusão como hipóxia, isquemia, injúria celular, apoptose celular e processos inflamatórios que cursam com necrose tubular aguda, presentes na fase 1 e 2 da injúria renal aguda, são importantes em cadelas com piometra e passíveis de serem identificadas com o exame de Dopplerfluxometria e mensuração do índice de resistividade renal. Segundo Morrow et al. (1996), um IR aumentado pode sugerir doença tubulointersticial ativa ou vascular. De maneira geral, quando substâncias vasoconstritoras são liberadas após uma lesão renal, o fluxo diastólico é reduzido, resultando em uma velocidade diastólica final mais baixa, o que leva ao aumento do índice de resistividade.

Embora o IR apresente valores maiores com o aumento da desidratação e com a diminuição da perfusão renal, este parâmetro apresentou baixa correlação com variáveis importantes para avaliação da função renal como demonstram as Figuras de 1 a 5. A correlação para estas variáveis foram relativamente mais homogêneas para valores proposto como padrões de normalidade, porém apresentou padrões aleatórios para valores referentes à presença de alterações. Na Figura 6, esta distribuição foi completamente dispersa, não havendo associação entre os valores de densidade urinária e o índice de resistividade da artéria renal principal.

Cadelas com piometra, apesar de desidratadas, apresentam a diminuição da concentração urinária, o que pode ser observado neste experimento, em que $83 \%$ das cadelas apresentaram valores de densidade urinária menores do que 1.025. Embora a explicação para esta perda de habilidade de concentração urinária ainda não esteja completamente elucidada, acredita-se que as cadelas com piometra apresentem algum grau de disfunção dos receptores de hormônio anti-diurético, o que também pode estar relacionado a endotoxemia decorrente das endotoxinas pro- duzidas pela Escherichia coli, principal agente infeccioso presente em cadelas com piometra (Asheim 1965, Heiene et al 2004).

Para o comprimento renal, não ocorreu diferença estatística de um rim para o outro, o que corrobora a alguns dados da literatura (Nyland et al. 1989, Sampaio \& Araújo 2002) e diverge de outros (Santana et al. 2009). No entanto, do momento 1 para o 2, ocorreu diferença estatística entre o comprimento renal, embora a média em números absolutos, aparentemente apresentasse valores semelhantes. 0 tamanho renal ainda é estudado na literatura e com frequência apresenta divergências entre os autores sobre a forma mais adequada de mensuração renal (Barr et al. 1990, Mareschal et al. 2007, Santana et al., 2009). Neste estudo, o objetivo foi verificar a diferença de um momento para o outro, já que as cadelas desidratadas diminuem a quantidade de fluxo sanguíneo renal. Na literatura, as alterações transitórias do tamanho renal estão relacionadas a diurese por furosemida e por agentes de contraste hipertônicos (Nyland \& Mattoon 2005). No presente estudo, as cadelas no momento 1 apresentaram valores de comprimento renal menores do que no momento 2 , o que poderia contribuir para a proposta de menor perfusão renal transitória. No entanto, não se pode afirmar a presença de aumento ou redução do tamanho renal individualmente, já que este tipo de avaliação não foi realizada.

Algumas das variáveis que avaliavam a morfologia renal no exame ultrassonográfico como arquitetura renal, contorno renal, definição corticomedular, relação corticomedular calcificação de divertículos não foram estatisticamente diferentes do momento 1 para o 2. Essas alterações são comuns em cadelas de meia idade a idosas devido as alterações de senescência e das possíveis enfermidades que estas cadelas apresentaram ao longo da vida, que mesmo de origem extrarrenal, podem cursar com danos renais, como nos casos de vômito e diarreia (Lees et al. 2005, Maddison 2008, Ross 2011).

As características que apresentaram diferença estatística de um momento para outro foram a ecotextura renal, presença de sinal de medular, dilatação de pelve e outras alterações como áreas de infartos e pontos hiperecogênicos difusos na cortical e/ou medular renal. Com exceção da ecotextura renal que estava mais homogênea no momento 2 , todas as outras característica aumentaram a incidência no momento 2, o que sugere maiores danos renais. 0 sinal da medular, pode estar relacionada a necrose tubular aguda e nefrite intersticial, alterações comuns em animais com injúria renal aguda (Ross 2011). A dilatação de pelve pode ser decorrente de pielonefrite, já que causas obstrutivas foram descartadas (Espada et al. 2006). Além disso, existem fatores de virulência da Escherichia coli, principal agente etiológico das cadelas com piometra, que predispõe a pielonefrite (Siqueira et al. 2009, Maddens et al. 2010). As áreas de infarto podem estar relacionadas à baixa perfusão renal, enquanto os pontos hiperecogênicos pode se referir a fibrose intersticial, achado comum no exame histopatológico dos rins de cadelas com piometra (Heiene et al. 2007, Maddens et al. 2011).

As alterações de ecogenicidade renal geralmente são 
inespecíficas e se referem ao aumento ou diminuição da ecogenicidade em relação a algum órgão, como baço e fígado (Nyland \& Mattoon 2005). No entanto, pesquisas recentes tem contestado os padrões estabelecidos na literatura (Ivancic \& Mai 2008). De uma forma geral, o aumento e a diminuição da ecogenicidade pode estar relacionado à nefrite intersticial e glomerular, a necrose tubular aguda e ao edema (Nyland \& Mattoon 2005, Espada et al. 2006), o que possivelmente ocorre nos rins das cadelas com injúria renal aguda (Ross 2011), como nos casos de piometra.

\section{CONCLUSÕES}

Os resultados do presente trabalho demonstram que a ultrassonografia Doppler permite identificar alterações de redução da perfusão renal, por meio do Doppler colorido e no aumento do índice de resistividade das artérias renais em cadelas com piometra.

A ultrassonografia modo B, embora apresente alterações inespecíficas, pode detectar alterações renais progressivas em cadelas com piometra.

A utilização dos exames laboratoriais para avaliação renal de cadelas com piometra deve ser completa, já que a incidência de cadelas azotêmicas é baixa em relação à identificação de alterações por outros métodos diagnósticos, o que demonstra que, mesmo sem aumento nos níveis séricos de ureia e creatinina, estas cadelas estão submetidas a injúria renal.

Agradecimentos.- À Fundação de Amparo à Pesquisa do Estado de São Paulo (FAPESP), pelo apoio financeiro que possibilitou a realização desse projeto (FAPESP processo 2010/03930-0). Ao Professor José Carlos Pantoja, FMVZ-Unesp, Botucatu, pela realização da estatística.

\section{REFERÊNCIAS}

Asheim A. 1965. Pathogenesis of renal damage and polydipsia in dogs with pyometra. J. Am. Vet. Med. Assoc. 147:736-745.

Barr F.J., Holt P.E. \& Gibbs C. 1990. Ultrasonographic measurement of normal renal parameters. J. Small Anim. Pract. 31:180-184.

Bartoskova A., Vitasek R., Leva L. \& Faldyna M. 2007. Hysterectomy leads to fast improvement of haematological and immunological parameters in bitches with pyometra. J. Small Anim. Pract. 48:564-568.

Beatrice L., Nizi F., Callegari D., Paltrinieri S., Zini E., D’Ippolito P. \& Zatelli A. 2010. Comparison of urine protein-to-creatinine ratio in urine samples collected by cystocentesis versus free catch in dogs. J. Am. Vet. Med. Assoc. 236:1221-1224.

Cançado R.D. \& Chiattone C.S. 2002. Anemia de Doença Crônica: revisão. Revta Bras. Hemat. Hemot. 24:127-36.

Espada Y., Novellas R. \& Gopegui R.R. 2006. Renal ultrasound in dogs and cats. Vet. Res. Commun. 30:133-137.

Hardy R.M. \& Osborne C.A. 1974. Canine pyometra: pathophysiology, diagnosis and treatment of uterine and extra-uterine lesions. J. Am. Anim. Hosp. Assoc. 10:245-268.

Heiene R. 1993. Urinary enzymes: how can they become useful in canine medicine? Proc. Annual Meeting European Society of Veterinary Nefrology and Urology, Berlin, DE, p.36-39.

Heiene R., Moe L. \& Molmen G. 2001. Calculation of urinary enzyme excretion, with renal structure and function in dogs with pyometra. Res. Vet. Sci. 70:129-137.

Heiene R., Van Vonderen I.K., Moe L., Molmen G.S., Larsen N.H. \& Kooistra H.S. 2004. Vasopressin secretion in response to osmotic stimulation and effects of desmopressin on urinary concentrating capacity in dogs with pyometra. Am. J. Vet. Res. 65:404-408.

Heiene R., Kristiansen V., Teige J. \& Jasen J.H. 2007. Renal histomorphology in dogs with pyometra and control dogs, and long term clinical outcome with respect to signs of kidney disease. Acta Vet. Scand. 19:13-22.

Ivancic M. \& Mai W. 2008. Qualitative and quantitative comparison of renal vs. hepatic ultrasonographic intensity in healthy dogs. Vet. Radiol. Ultrasound 49:368-373.

Lees G.E., Brown S.A., Elliot J., Grauer G.E. \& Vaden S.L. 2005. Assessment and management of proteinuria in dogs and cats. J. Vet. Intern. Med. 19:377-385

Maddens B., Daminet S., Smets P. \& Meyer E. 2010. Escherichia coli pyometra induces transient glomerular and tubular dysfunction in dogs. J. Vet. Med. 24:1263-1270.

Maddens B., Heiene R., Smets P., Svensson M., Aresu L., Van der Lugt J., Daminet S. \& Meyer E. 2011. Evaluation of kidney injury in dogs with pyometra based on proteinuria, renal histomorphology, and urinary biomarkers. J. Vet. Intern. Med. 25:1075-1083.

Maddison J.E. 2008. Interpreting the numbers: azotemia and urine specific gravity. Proc. $33^{\text {th }}$ Annual World Small Animal Veterinary Congress, São Paulo, SP, p.558-559.

Mareschal A., D’Anjou M.A., Moreau M., Alexander K. \& Beauregard G. 2007. Ultrasonographic measurement of kidney to aorta ratio as a method of estimating renal size in dogs. Vet. Radiol. Ultrasound 48:434-438.

Morrow K.L., Salman M.D., Lappin M.R. \& Wrigley R. 1996. Comparison of the resistive index and clinical parameters in dogs with renal disease. Vet. Radiol. Ultrasound 37:193-199.

Novellas R., Espada Y. \& Gopegui R.R. 2007. Doppler ultrasonographic estimation of renal and ocular resistive and pulsatility indices in normal dogs and cats. Vet. Radiol. Ultrasound 48:69-73.

Nyland T.G. \& Mattoon J.S. 2005 Ultra-som Diagnóstico em Pequenos Animais. Roca, São Paulo, p.161-198.

Nyland T.G., Kantrowitz B.M. \& Fisher P. 1989. Ultrasonic determination of kidney volume in the dog. Vet. Radiol. Ultrasound 30:174-180.

Pretzer S.D. 2008. Clinical presentation of canine pyometra and mucometra: a review. Theriogenology 70:359-363.

Rivers B.J., Walter P.A., Polzin D.J. \& King V.L. 1997. Duplex Doppler estimation of intrarenal Pourcelot resistive index in dogs and cats with renal disease. J. Vet. Intern. Med. 11:250-260.

Ross L. 2011. Acute kidney injury in dogs and cats. Vet. Clin. Small Anim. Pract. 41:1-14.

Sampaio K.M.O.R. \& Araújo R.B. 2002. Ultra-sonografia de características lineares e estimativa do volume de rins de cães. Arq. Bras. Med. Vet. Zootec. 54:248-254.

Sandholm M., Vasenius H. \& Kivisto A.K. 1975. Pathogenesis of canine pyometra. J. Am. Vet. Med. Assoc. 167:1006-1010.

Santana E.J.M., Beserra P.S., Brito A.B., Miranda S.A., Nikolak E. \& Domingues S.F.S. 2009. Triplex Doppler da artéria renal e a relação entre a ecobiometria dos rins com a distância atlanto-coccígea e altura em Canis familiaris. Pesq. Vet. Bras. 29(10):809-815.

Siqueira A.K., Ribeiro M.G., Leite D.S., Tiba M.R., Moura C., Lopes M.D., Prestes N.C., Salerno T. \& Silva A.V. 2009. Virulence factors in Escherichia coli strains isolated from urinary tract infection and pyometra cases and from feces of healthy dogs. Res. Vet. Sci. 86:206-210.

Smith F.O. 2006. Canine pyometra. Theriogenology 66:610-612.

Stone E.A., Littman M.P.. Robertson J.L. \& Bovée K.C. 1988. Renal dysfunction in dogs with pyometra. J. Am. Vet. Med. Assoc. 193:457-467.

Szatmári V., Sótonyi P. \& Voros K. 2001. Normal duplex Doppler waveforms of major abdominal blood vessels in dogs: a review. Vet. Radiol. Ultrasound 42:93-107.

Yoo S.Y., Kim I.O. \& Kim Y. 2008. Power Doppler imaging in acute renal vein occlusion and recanalization: a canine model. Kor. J. Radiol. 9:128133. 